\title{
Low-Resistivity Indium-Tin-Oxide Transparent Conducting Films: Dependence of Carrier Electron Concentration on Tin Concentration
}

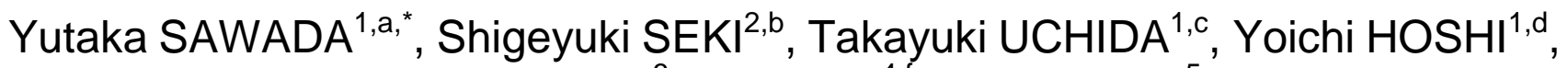 \\ Mei-Han WANG ${ }^{3, \mathrm{e}}$, Hao LEI ${ }^{4, \mathrm{f}}$, Li-Xian SUN ${ }^{5, \mathrm{~g}}$ \\ ${ }^{1}$ Center for Hyper Media Research, Tokyo Polytechnic University, Atsugi, Kanagawa, Japan \\ ${ }^{2}$ Department of Electronic Engineering, Sendai National College of Technology, Sendai, Japan \\ ${ }^{3}$ Scool of Mechanical Engineering, Shenyang University, Shenyang, China \\ ${ }^{4}$ Suraface Engineering of Materials Division, Institute of Metal Research, Chinese Academy of \\ Sciences, Shenyang, China \\ ${ }^{5}$ School of Material Science and Engineering and Guangxi Key Laboratory of Information Materials, \\ Guilin University of Electronic Technology, Guilin, China

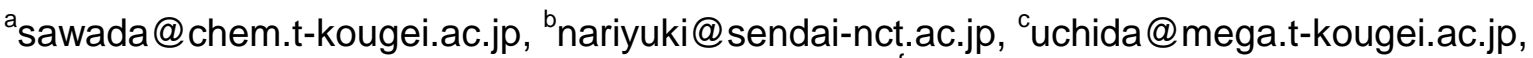
dhoshi@em.t-kougei.ac.jp, ${ }^{\mathrm{e}}$ wangmhdicp@aliyun.com, ${ }^{\mathrm{f}}$ haolei@imr.ac.cn, ${ }^{9}$ sunlx@guet.edu.cn
}

${ }^{*}$ Corresponding author

Keywords: ITO, Tin-doped $\ln _{2} \mathrm{O}_{3}$, Spray chemical vapor deposition.

\begin{abstract}
Indium-Tin-Oxide (ITO, tin-doped $\left.\mathrm{In}_{2} \mathrm{O}_{3}\right)$ films with low resistivity $\left(7.7 \times 10^{-5} \mathrm{ohm} \mathrm{cm}\right)$ and high carrier electron concentration $\left(1.8 \times 10^{21} \mathrm{~cm}^{-3}\right)$ was successfully prepared by spray chemical vapor deposision in air and post-deposition annealing in reducing atmosphere in our previous papers; Y. Sawada et al., Thin Solid Films, 409 (2002) 46-50 and Y. Sawada, Materials Sci. Forum, 437-438 (2003) 23-26. Doping one tin ion generated two carrier electrons at low concentration of tin. The relation between carrier electron concentration and tin concentration are discussed in the present paper to propose a nobel defect model.
\end{abstract}

\section{Introduction}

Transparent conducting films of tin-doped $\mathrm{In}_{2} \mathrm{O}_{3}$ (Indium-Tin-Oxide, ITO) are used for solar cells, flat panel displays including touch panels etc. and usually deposited by magnetron sputtering. The authors reported elsewhere [1,2] low-resistivity ITO films fabricated by spray chemical vapor deposition very cheaply. The lowest resistivity of the as-deposited in air was $1.8 \times 10^{-4} \Omega \cdot \mathrm{cm}$. This value was compatible with those deposited by magnetron sputtering. The post-deposition annealing in reducing atmosphere lowered the resistivity. The lowest resistivity was $7.7 \times 10^{-5} \Omega \cdot \mathrm{cm}$. In the present paper the carrier electron concentration of ITO films after the post-deposition annealing will be discussed as a function of tin concentration.

\section{Experimental}

The preparation and evaluation of the films were reported elsewhere [1, 2] in detail. Ethanol solution of $\mathrm{InCl}_{3} \cdot 2.7 \mathrm{H}_{2} \mathrm{O}$ and $\mathrm{SnCl}_{2} \cdot 0.86 \mathrm{H}_{2} \mathrm{O}$ was sprayed onto a glass substrate (Corning 7059) heated at $300-350^{\circ} \mathrm{C}$ on a hotplate to deposit ITO films (approx. $200 \mathrm{~nm}$ ). The films were annealed at $600^{\circ} \mathrm{C}$ for $2 \mathrm{~h}$ in $\mathrm{N}_{2}-0.2 \% \mathrm{H}_{2}$ gas flow $(300 \mathrm{~mL} / \mathrm{min})$ to lower the resistivity.

\section{Results and Discussion}

Figure 1 shows carrier electron concentration (n) of indium oxide films as a function of tin concentration $\left(\mathrm{C}_{\mathrm{Sn}}\right)$ after annealing in reducing atmosphere. The $\mathrm{C}_{\mathrm{Sn}}$ is tin concentration of 
$100 \times[\operatorname{Sn}] /([\mathrm{Sn}]+[\mathrm{In}])$, where $[\mathrm{Sn}]$ and $[\mathrm{In}]$ are the concentration $\left(\mathrm{cm}^{-3}\right)$ of tin and indium atoms, respectively, in indium oxide crystal.

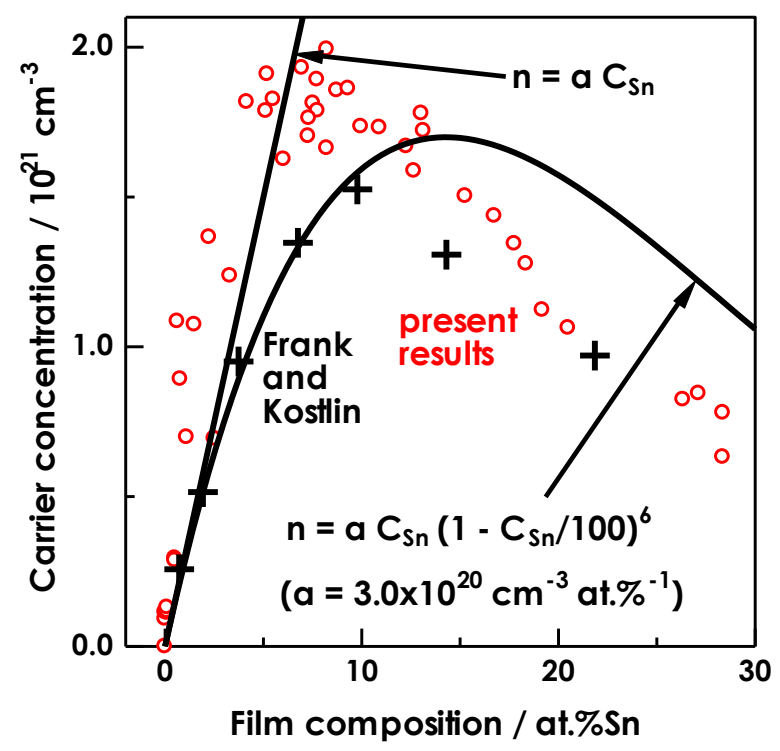

Fig. 1. Carrier electron concentration of indium oxide films as a function of tin concentration after annealing in reducing atmosphere: comparison with the results by Frank and Köstlin

This figure also shows the results by Frank and Köstlin [3] who deposited by spray CVD and annealed in reducing atmosphere. They interpreted that a $\mathrm{Sn}^{4+}$ ion at a $\mathrm{In}^{3+}$ site genaerates one carrier electron when interaction is negligible between the two neighbouring $\mathrm{Sn}^{4+}$ ions at low concentration of tin. This is expressed as Eq. 1 by Kröger-Vink notation [4] at low tin concentration.

$$
\mathrm{SnO}_{2} \rightarrow \mathrm{Sn}_{\mathrm{In}}^{\cdot}+(3 / 2) \mathrm{O}^{\times}+\mathrm{e}^{\prime}+(1 / 4) \mathrm{O}_{2}
$$

Carrier electron concentration (n) is expressed as

$$
\mathrm{n}=[\mathrm{Sn}]=\mathrm{a} \mathrm{CSn}
$$

The constant $a=3.0 \times 10^{20} \mathrm{~cm}^{-3}$ at. $\%^{-1}$ is determined from the lattice constant $\left(1.0118 \times 10^{-7} \mathrm{~cm}\right)$ of $\mathrm{In}_{2} \mathrm{O}_{3}$ and number of metal ions (32) in a unit cell. At higher concentration of tin, carrier electron concentration is deviates from Eq. 2 . They attributed to a formation of neutral defect complex $\mathrm{Sn}_{\text {In } 2}$ $\mathrm{O}_{\mathrm{i}}^{\times}$". They assumed two nearest-neighbor $\mathrm{Sn}^{4+}$ ions at $\mathrm{In}^{3+}$ site coupled with one interstitial $\mathrm{O}^{2-}$ ions to eliminate carrier electrons as Eq. 3.

$$
2 \mathrm{Sn} \cdot \mathrm{In}+2 \mathrm{e}^{\prime}+(1 / 2) \mathrm{O} 2 \rightarrow \mathrm{Sn} \cdot \mathrm{In} 2 \mathrm{O} \times \mathrm{i}^{\prime}
$$

The $\mathrm{O}^{\times}$" " is an interstitial oxygen ion $\left(\mathrm{O}^{2-}\right)$ located at a space called quasi-anion site of $\operatorname{In}_{2} \mathrm{O}_{3}$ lattice (C-rare earth oxide structure). They assumed that tin ions occupy only at "b-site" of $\operatorname{In}_{2} \mathrm{O}_{3}$ lattice and proposed Eq. 4 with 6 nearest-neighbor tin ions.

$$
\mathrm{n}=\mathrm{a} \operatorname{CSn}(1-\operatorname{CSn} / 100) 6
$$

This equation satisfies their results at $\leq$ approx. 10 at.\% Sn but fails to explain higher carrier electron concentrations of the present results.

The present results are shown in Figure 2 in order to compare with the results by Ohta et al. who deposited ITO film on a single crystal of zirconia by expensive pulsed laser deposition [5]. The 
present highest value $\left(1.8 \times 10^{21} \mathrm{~cm}^{-3}\right)$ agreed with their ones and our previous result $[1,2]$ at $\mathrm{C}_{\mathrm{Sn}}, 5-7$ at.\%. The results fit with Eq. 5 at low concentration of tin (< approx. 3 at.\%).

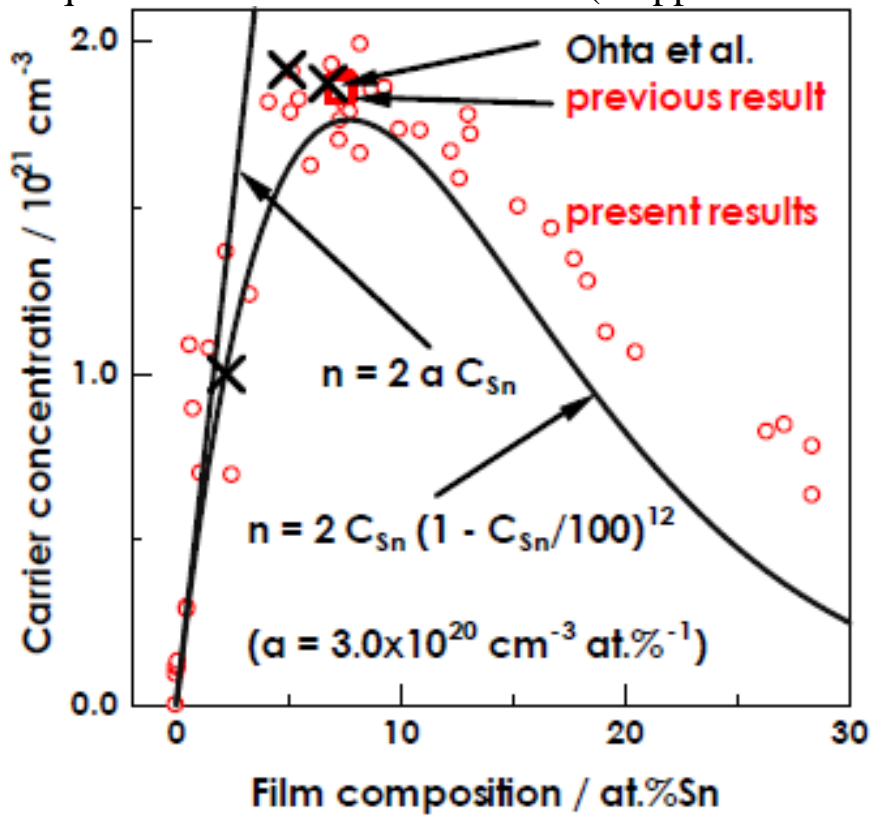

Fig. 2. Carrier electron concentration of indium oxide films as a function of tin concentration after annearing in reducing atmosphere: comparison with the results by Ohta et al. and our previous result.

$$
\mathrm{n}=2[\mathrm{Sn}]=2 \mathrm{aCSn}
$$

This assumes that doping one tetravalent tin ion $\left(\mathrm{Sn}^{4+}\right)$ generates two carrier electrons $\left(\mathrm{e}^{-}\right)$although it seems rather strange. In order to explain the present high carrier concentration, simulataneous formation of $\mathrm{Sn}_{\text {In }}{ }_{\text {and }} \mathrm{V}_{\mathrm{O}}^{\circ}$ was tentatively assumed to generate two carrier electrons as Eq. 6

$$
\mathrm{SnO} 2 \rightarrow \mathrm{Sn} \bullet \mathrm{In}+(1 / 2) \mathrm{O} \times \mathrm{O}+\mathrm{V} \cdot \mathrm{O}+2 \mathrm{e}^{\prime}+(3 / 4) \mathrm{O} 2
$$

$\mathrm{V}^{*}$ is an oxygen ion vacancy coupled with an electron. A novel model with 12 nearest-neighbor tin ions (both b- and d-site) is proposed.

$$
\mathrm{n}=2 \mathrm{a} \operatorname{CSn}(1-\operatorname{CSn} / 100) 12
$$

This is a better fit with the present results although the defect mechanism explaining the phenomenon is not clear at present.

Structure and other properties of the present films will be demonstrated: the resistivity, carrier electron mobility, transmittance and reflectance, X-ray diffraction, FE-SEM photos etc.

\section{Acknowledgements}

The authors thank Mr. Takeshi AOYAMA for film preparation and Mr. Yoshiyuki SEKI for technical advice.

\section{References}

[1] Y. Sawada, C. Kobayashi, S. Seki and H. Funakubo, Thin Solid Films, 409 (2002) 46-50.

[2] Y. Sawada, Materials Sci. Forum, 437-438 (2003) 23-26.

[3] G. Frank and H. Köstlin, Appl. Phys., A27 (1982) 69-75. 
[4] F. A. Kröger, "Chemistry of Imperfect Crystals, Vol. 2" (North-Holland, Amsterdam 1974) pp. 690-694.

[5] H. Ohta, M. Orita, M. Hirano, H. Tanji, H. Kawazoe and H. Hosono, Appl. Phys. Lett., 76 (2000) 2740-2742. 